\title{
Frustration in Switzerland
}

\section{Zurich}

As part of its 700-year anniversary celebration, Switzerland last month opened a huge and unique science exhibition on the outskirts of Zurich. Called Heureka after the German-language version of Archimedes' famous cry, the exhibition departs from the historical approach of many science museums and instead attempts to show the joys and anxieties of 'living science' by having researchers themselves show what they do to the public.

After the first month of the exhibition, the state of the art. The result is that many of the 'experiments' allow visitors to do no more than push a button that causes some preordained, complex process to be carried out before their eyes. This is the case in displays on nuclear fusion and genetic engineering.

Furthermore, technical terms such as 'plasmid' are frequently used in the displays without definitions, leading many visitors to walk away in frustration.

More successful in the eyes of visitors are engineering projects like avalanche barriers

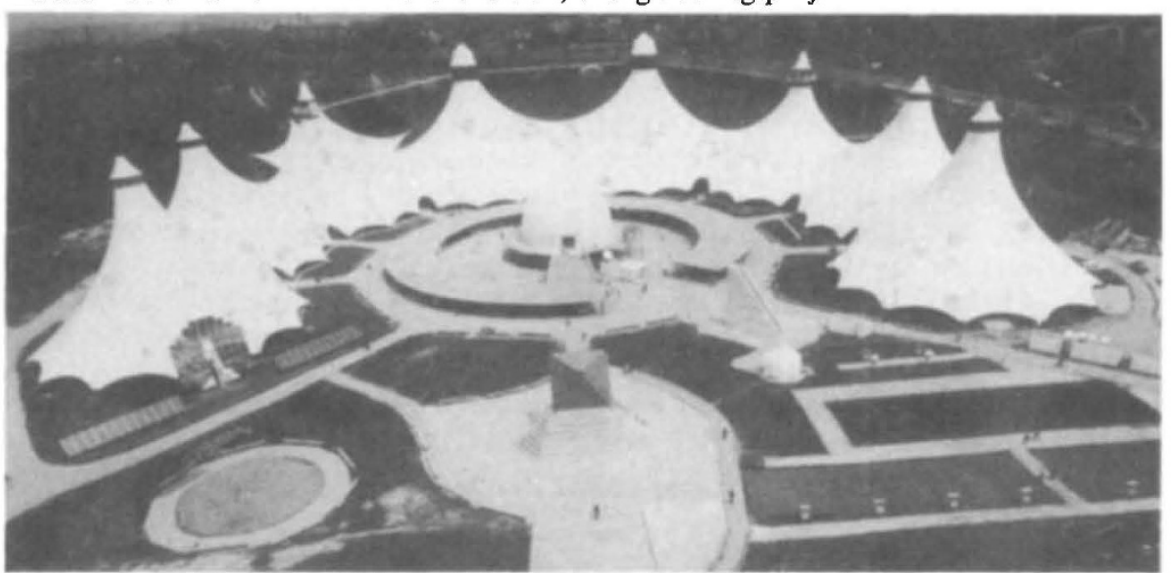

Eureka: Swiss birthday exhibition fails to displace the public's emotions

however, the encounter has left both sides feeling frustrated.

Researchers who contributed to the exhibition say they have been disappointed in just how uninterested people are in what they are doing. After five days of displaying a working laboratory model of a scanning tunnelling microscope, physicist Michele Bernasconi of the University of Basle says it is depressing how little people want to know.

Bernasconi says that "it took six months to build this display" of the microscope, "but I have only had a few questions a day. People seem afraid to ask me anything." Bernasconi's experience is typical of those reported by researchers at Heureka.

On the other hand, many visitors say they feel baffled by what the researchers are presenting. "We saw everything but understood very little," was the most common response of those interviewed.

The exhibits for the most part assumed too much background knowledge, said Christian Good, a visitor from Zurich, so that a person without a university education would generally be lost.

Biologist Isabelle Dusart of France agrees: "Without the training in physics that was required of me as a biologist, I wouldn't be able to understand what the physicists are presenting here."

The problems of Heureka show just how difficult it is to communicate about science to the public. Part of the problem is that the designers of Heureka tried to make every exhibit interactive and yet also reflective of that can measure the weight of fallen snow or a futuristic tandem bicycle that allows visitors to test their pedalling efficiency.

That the two sides are somehow missing each other at Heureka is reflected in the low number of visitors who have so far attended - just 62,000 in the first four weeks, an average of about 2,000 people a day. In order to break even on the SF30 million (\$20 million) exhibition, says Heureka director Georg Müller, it will require 6,000 visitors per day throughout the summer months.

Müller, whose experience in directing a highly successful hands-on science exhibition called 'Phenomena' in Zurich in 1984 made him the prime candidate to put on Heureka, defends the premise of Heureka and says he is convinced that the exhibition will become more popular after a number of initial kinks have been worked out.

Ironically, the historical portion of the exhibition - housed in a rough wood spiral construct called Galileo's Tower, complete with internal staircase - has been a much bigger hit with the public than the current experiments. The tower features hands-on demonstrations of machines ranging from pulleys to telescopes, as well as demonstrations of basic chemistry that have proven very popular. It is, says one researcher who helped set up the exhibition, as if people's scientific intuition has reached only a point somewhere in the seventeenth and eighteenth century, and so they are only comfortable with experiments that date from that time.

Steven Dickman

\section{Japanese biologists produce 'hot' papers}

\section{Tokyo}

THE common perception that Japan is strong in engineering and applied science but weak in basic research is turned upside down in a recent survey of the 'hottest' research papers coming out of Japan by the Washington-based Science Watch journal.

In its recently released April issue, the journal's analysis of current 'hot' papers, defined as papers published between 1988 and 1990 that receive many more citations than average from other authors, reveals that Japan is strongest in basic research in biochemistry, molecular biology, and pharmacology, and weakest in engineering, technology and applied science.

Out of 42 hot papers from Japan in Science Watch's worldwide database of 900 hot papers, 25 were in the life sciences. This is considerably more than the 15 that would be expected based on the percentage of all Japanese papers in this field. In contrast, there is only one hot paper in engineering, technology and applied science, as opposed to the six expected.

The University of Tsukuba ranks highest among Japanese universities with 5 hot papers on endothelins - powerful peptides that raise blood pressure and reduce circulation. A string of recent papers by a group led by Tomoh Masaki at the university have stirred tremendous interest worldwide, partly because of the potential application of the research to treatment of heart disease, but also because the research is widely recognized as being a substantial contribution to understanding the fundamental biochemistry, molecular biology and pharmacology of these important peptides (see Nature 348, 673; 1990). Researchers at the University of Osaka also do well, with 5 top papers covering, among other things, research on interleukins.

A closer look at the ratings of scientific papers shows that the common perception about Japan's strength in applied science does have a basis in reality, however. When Science Watch looked at the average number of citations per paper for all papers regardless of their quality, Japan came out strongest in engineering, technology and applied science, with 11 per cent above the average worldwide citation score per paper. By the same measure, Japan was weakest in the life sciences with 26 per cent below the average number of citations.

It is only when the database is reduced to a limited number of hot papers with aboveaverage scores that the life sciences come out on top. In short, the journal concludes that "technology reigns supreme when one considers Japanese research as a whole," but "life sciences top the chart when one looks at Japan's creme de la creme."

David Swinbanks 